\title{
Esophageal Injury Secondary to Severely Embedded Denture: A Case Report
}

Santiyamadhi Subramanyan ${ }^{1}$, Komathi Ramachandran², Ing Ping Tang ${ }^{3}$

\begin{abstract}
$\underline{\text { Abstract }}$
The incidence of esophageal impacted denture is proportionately increasing as there is increasing number of people wearing denture in current days. Impacted denture has to be removed as soon as possible because the delay can lead to complications. The successful removal of impacted denture in the esophagus in a patient is reported, with a review of the literature. A 52-year-old Malay lady complained of dysphagia with no history of foreign body ingestion. Following unsuccessful attempts of removal via a rigid esophagoscope, open surgery was performed. Without further delay, the impacted denture was removed by cervical esophagotomy, and the patient recovered uneventfully. Esophageal foreign bodies are usually removed by endoscopy. However, in situations where this appears potentially hazardous, such as with impacted denture, open surgical extraction that is promptly performed is a safer option.
\end{abstract}

Kevwords: Embedded denture, esophageal perforation, radio-opaque, esophagotomy.

International Journal of Human and Health Sciences Vol. 05 No. 02 April'21 Page : 362-365 DOI: http://dx.doi.org/10.31344/ijhhs.v5i3.289

\section{Introduction:}

Foreign body ingestion is one of the common acute laryngological problem requiring immediate attention. Failure to treat this emergency can cause significant complications, morbidity and mortality. ${ }^{1}$ The presence of foreign body for longer than 24 hours increases the risk of complications and thus early intervention is required.

Usually, incidence such as esophageal perforation, mediastinitis, sepsis, or death are rare. In one series, the complications associated with foreign bodies impaction were reported to be ulcers $(21.2 \%)$, lacerations $(14.9 \%)$, erosions $(12 \%)$, and perforation $(1.9 \%) .{ }^{2}$ We report a case of a patient with a prolonged embedded denture causing esophageal injury requiring open surgery and esophageal repair.

\section{Case Report:}

44-year old homemaker with no underlying medical condition presented with dysphagia and odynophagia of 4 months duration associated with significant weight loss of $30 \mathrm{kgs}$ in past 4 months. Patient gave no history of ingestion of any foreign body or dentures. She had presented 3 months ago at periphery clinic with dysphagia. Subsequently was seen at our centre as she had difficulty to drink fluids and had excessive salivation. A flexible scope revealed normal findings. An OGDS was performed which showed impacted foreign body at $15 \mathrm{~cm}$ from incisors at esophagus level. X-ray

1. MBBS, Medical Officer, Department of Otorhinolaryngology-Head and Neck, Sarawak General Hospital, Jalan Hospital, 93586 Kuching, Malaysia.

2. MS ORL-HNS, Specialist, Department of Otorhinolaryngology-Head and Neck, Sarawak General Hospital, Jalan Hospital, 93586 Kuching, Sarawak, Malaysia.

3. MS ORL-HNS, Associate Professor \& Consultant, Department of Otorhinolaryngology-Head and Neck, Faculty of Medicine \& Health Sciences, University Malaysia Sarawak, Jalan Datuk Mohammad Musa, 94300 Kota Samarahan, Sarawak, Malaysia.

Correspondence to: Santiyamadhi Subramanyan, MBBS, Medical Officer, Department of Otorhinolaryngology-Head and Neck, Sarawak General Hospital, Jalan Hospital, 93586 Kuching, Malaysia. E-mail: santiya.dr@gmail.com 
did not reveal any metallic wire or radio-opaque lesion. Emergency endoscopic removal was attempted under general anaesthesia which showed a denture embedded at $20 \mathrm{~cm}$ from incisor with surrounding inflammation and fibrosis reaction to the denture has occurred in the esophageal mucosa. Due to difficulty in visualizing the wire or hooks of the denture, care was taken not to injure the esophageal mucosa while removing the denture. Endoscopic removal with forceps was unsuccessful in dislodging the denture. Decision was made to proceed with open transcervical esophagostomy to remove the denture. The denture is a $3 \mathrm{~cm}$ acrylic embedded deeply into the esophageal mucosa laterally abutting into the tracheal wall. Upon removal of the denture noted the wire had perforated the esophagus. Therefore esophagus was repaired in 2 layers. Neck incision was closed with drain in situ and a diagnostic bronchoscopy revealed granulation and fibrosis at posterior wall of trachea at the site of embedded denture. Tracheostomy was done, a nasogastric tube was not able to be inserted due to prolonged constrictions. Post operatively intravenous antibiotics and total parenteral nutrition was given. An OGDS was performed 2 weeks post exploration which showed tiny leakage at the repair site and nasogastric tube inserted successfully. Flexible bronchoscope revealed fistula about $2 \mathrm{~cm}$ from tracheostoma site inferiorly. Patient was discharged with nasogastric feeding and tracheostomy tube. She was seen weekly at our clinic with regular flexible scope assessment. Gastrograffin studies was performed

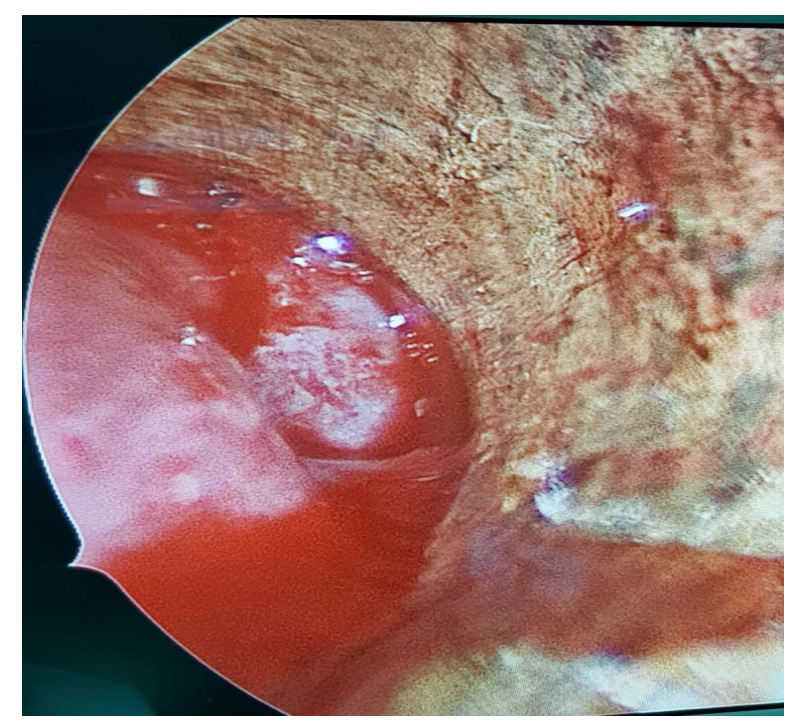

Figure 1: Endoscopic image showing embedded denture with surrounding fibrosis.
2 months post removal which showed no fistula or any leakage from repair site. At 4 months post operatively patient was weaned off nasogastric tube and tracheostomy tube. Clinically patient was able to eat solid foods and had gained weight and able to live normal lifestyle.

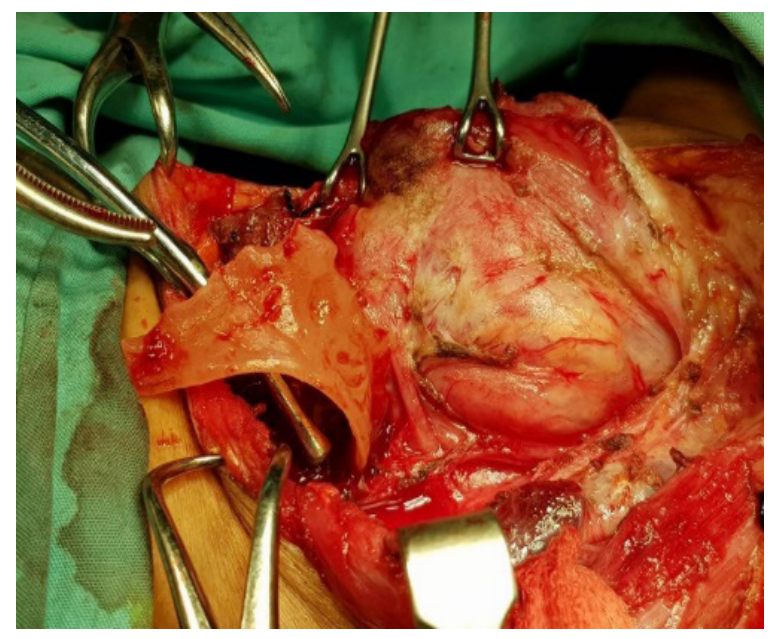

Figure 2: Intraoperative photograph showing denture being retrived via esophagotomy.

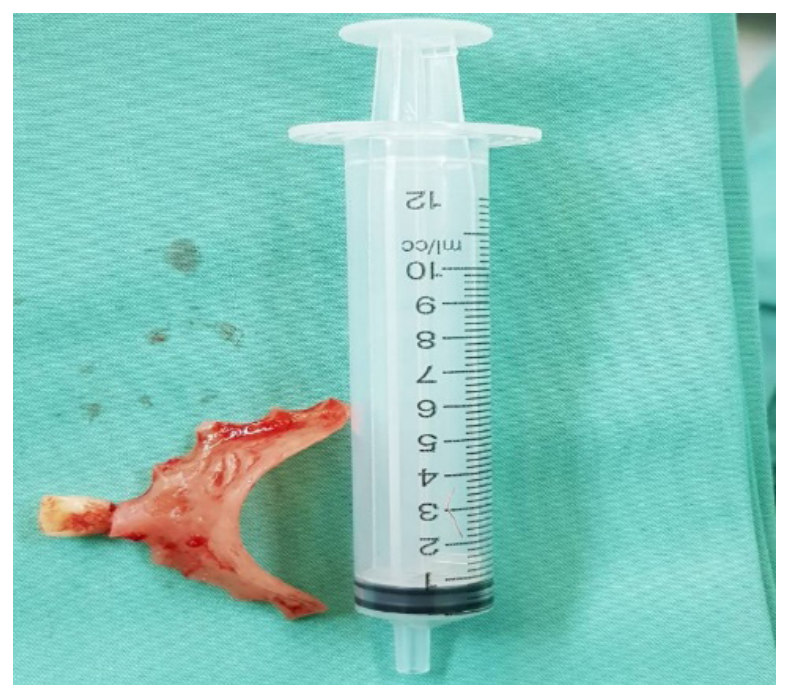

Figure 3: Denture measuring about $6 \mathrm{~cm} \mathrm{x} 4 \mathrm{~cm}$ lodged at cervical esophagus.

\section{Discussion:}

Meat is the most commonly impacted food bolus found in the esophagus in the elderly, which attributes to the usage of the denture. Denture regarded as a risk factor in that it reduces palatal tactile sensation and impairs mastication. ${ }^{3}$ As reported by Cheng and Tam the most commonly ingested foreign bodies by children were coins $(49 \%)$ and fish bone $(29 \%)$ respectively. ${ }^{4}$

Following foreign body ingestion, patients usually present with dysphagia (92\%) and pain 
over the neck $(60 \%) .{ }^{5}$ Other symptoms include hypersalivation, retrosternal fullness, regurgitation and odynophagia. Stridor and dyspnea may be encountered in pediatric patients due to tracheal compression. If the patient is able to give a reliable history, diagnosis is easily obtained which was failed in this case with our patient. The exact site of radio-opaque impacted foreign body can be determined with imaging, as well as air entrapment if there is perforation. Dentures, however, are frequently made of acrylic resin which is radiolucent, ${ }^{6}$ though the radio-opaque wire clasps of the denture are occasionally seen, if present as in this patient. Due to its large size, sharp edges, metal clasps, endoscopic extraction of dentures carries a high risk of esophageal perforation of $23 \%{ }^{6,7}$ Successful endoscopic extraction requires considerable experience, good visualization during rigid esophagoscopy and the use of shears forceps ${ }^{7}$. Removal by cervical esophagotomy by an experienced surgeon is a prudent option if any of the conditions are lacking. In our patient, the denture wire causing impaction could not be visualized and hence, there was no means of removing it endoscopically. In addition to esophagoscope, barium swallow and computed tomography should be considered to see the adjacent structure involvement and the extent of the tear. Multi detector row computed tomography is an essential investigation in the detection of pharyngoesophageal foreign bodies and aids in the management of complicated cases especially sharp or pointed ingested foreign bodies. ${ }^{8}$

Most swallowed foreign bodies are impacted at the cervical and upper esophagus and can be removed by cervical esophagotomy without thoracotomy. Nonetheless, esophagotomy has the risk of esophageal leakage which is potentially lethal. To circumvent this complication, open surgery for impacted foreign body should be done by an experienced surgeon. Delayed treatment of impacted foreign body leads to perforation and necrosis of esophageal wall, ${ }^{9}$ and may result in mediastinitis. At this stage, surgery may lead to esophageal leakage and mortality.

The experience of our case exemplifies that prompt management of an impacted denture in the esophagus leads to uneventful recovery. When endoscopic extraction is not feasible, immediate open surgical extraction should be carried out. As in this case, its highlighted that no computed tomography imaging was done but was proceeded with immediate removal of the foreign body. High suspicion and earlier intervention is the keynote for prevention of esophageal complications.

\section{Conclusion:}

In conclusion, foreign body impaction in the esophagus is often an emergency which causes mild or severe symptoms. The crucial point is to differentiate those that must be immediately removed from those requiring simple observation. If the patient has breathing problem and cannot swallow saliva, immediate treatment is mandatory because of high risk of inhalation. Cervical esophagotomy can be a safe and viable approach for extraction of foreign bodies, especially in cases when an endoscopic approach was not successful and the risk of complications is high. Surgery can be life-saving with minor postoperative complications if it is accompanied by appropriate antibiotic therapy.

\section{Conflict of Interest}

No conflict of interest has been disclosed by the authors.

\section{Authors Contributions}

Conception and design: SS; Collection and assembly of data: SS, KR; Critical revision of the article for important intellectual content: SS, KR, IPT.

\section{Funds}

This study did not receive any funding.

\section{Ethical approval}

Not required. 


\section{References:}

1. Cianci P, Tartaglia N, Altamura A et al. Cervical Esophagotomy for Foreign Body Extraction: A Case Report and Extensive Literature Review of the Last 20 Years. Am J Case Rep, 2018;19:400-5.

2. Sung SH, Jeon SW, Son HS et al. Factors predictive of risk for complications in patients with oesophageal foreign bodies. Dig Liver Dis, 2011;43:632-35.

3. Schneider EL, Guralnik JM. The aging of America. Impact on health care costs. JAMA 1990;263:2335-40.

4. Cheng W, Tam PK. Foreign-body ingestion in children experience with 1265 cases. J Pediatric Surg 1999;34:1472-6.

5. Khan MA, Hameed A, Choudhry AJ. Management of foreign bodies in the esophagus. J Coll Physicians Surg Pak 2004;14:218-20.

6. Nwafo DC, Anyanwu CH, Egbue MO. Impacted esophageal foreign bodies of dental origin. Ann Otol Rhinol Laryngol 1980;89:129-31.

7. Nwaorgu OG, Onakoya PA, Sogebi OA, Kokong DD, Dosumu OO. Esophageal impacted dentures. J Natl Med Assoc 2004;96:1350-3.

8. Pinto A, Muzj C, Gagliardi $N$ et al. Role of Imaging in the Assessment of Impacted Foreign Bodies in the Hypopharynx and Cervical Esophagus. Semin Ultrasound CT MRI 2012;33:463-470.

9. AbdullahBJ, TeongLK, Mahadevan J, Jalaludin A. Dental prosthesis ingested and impacted in the esophagus and orolaryngopharynx. J Otolaryngol 1998;27:190-4. 